The effect of non- uni for m nagnet $i$ zat $i$ on of per manent magnets on the perfor mance of a repul si ve type magnet i c bearing system

\begin{tabular}{|c|c|}
\hline 著者 & $\begin{array}{l}\text { Ohj i T., Kano M, Mikhopadhy ay S. C., I wahar a } \\
\text { Masay oshi, Yamada Sot oshi }\end{array}$ \\
\hline 著者別表示 & 岩原 正吉, 山田 外史 \\
\hline $\begin{array}{l}\text { j our nal or } \\
\text { publ i cat i on titl e }\end{array}$ & $\begin{array}{l}\text { I nt er nat i onal J our nal of Appl i ed } \\
\text { El ect r omagnet i cs and Mechani cs }\end{array}$ \\
\hline vol une & 11 \\
\hline nunber & 4 \\
\hline page $r$ ange & $255-259$ \\
\hline year & 2000 \\
\hline URL & ht t p: //doi . or g/10. 24517/00049211 \\
\hline
\end{tabular}




\title{
The effect of non-uniform magnetization of permanent magnets on the performance of a repulsive type magnetic bearing system
}

\author{
T. Ohji, M. Kano, S.C. Mukhopadhyay, M. Iwahara and S. Yamada \\ Laboratory of Magnetic Field Control and Applications, Faculty of Engineering, Kanazawa University, \\ Kodatsuno 2-40-20, Kanazawa 920-8667, Japan
}

\begin{abstract}
A permanent magnet bearing (MB) system utilizing the repulsive forces operating between the stator and rotor permanent magnet for levitation and radial control has been fabricated in our laboratory. The consistency of the permanent magnet magnetization effects the continuous steady-state and dynamic performance of the system. Since both the magnets are repelling each other, there will be demagnetization of the magnetization of the permanent magnet. Due to demagnetization or ageing or manufacturing asymmetry, the field distribution may not be uniform along the periphery of the magnet. In this paper the effect of this magnetization non-uniformity on the performances of the bearing system has been studied.
\end{abstract}

\section{Introduction}

Last few years the authors are engaged on the research and development of repulsive type magnetic bearing systems [1,2]. In repulsive type magnetic bearing system the permanent magnets are used for the levitation of the rotor and the system is stable along the radial direction. Therefore, this type of magnetic bearing system is superior to other magnetic bearings due to the small number of displacement sensors, control circuits, power amplifiers, A/D and D/A converters because of only axial active control by using the electromagnet [3]. This system can be applied to the uninterrupted power supply and flywheel energy storage [4].

The forces acting between the stator and rotor permanent magnets along the radial direction are totally balanced and as a result the rotor is positioned in the center of the stator. This is based on the assumption that the magnetization of the stator and rotor permanent magnets is uniform.

Since both the magnets are repelling each other, there are high chances of demagnetization of the permanent magnet. Even with ageing there may be demagnetization. There may be magnetization asymmetry due to some manufacturing defect or fabrication difficulties. Whatever may be the reason, this non-uniformity of magnetization has some effect on the performances on the bearing system. There will be oscillations of the rotor and in the worst case the rotor may hit the stator inner surface. The authors intend to study the above effect with the help of field analysis. The experiment has also been conducted for the observation. 


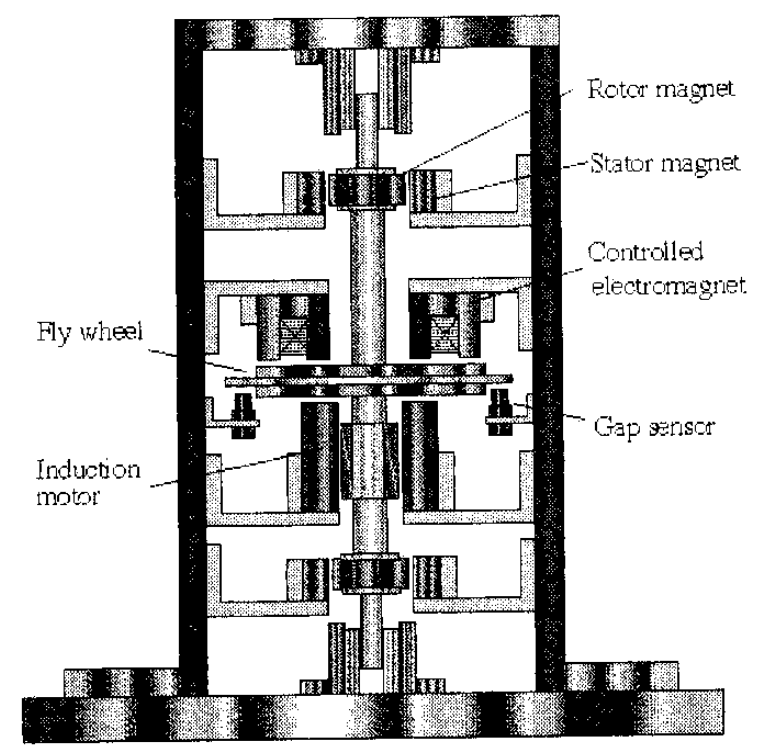

Fig. 1. Repulsive type magnetic bearing system.

\section{System description}

The magnetic bearing system fabricated and developed in our laboratory is shown in Fig. 1 and the corresponding permanent magnet configuration is shown in Fig. 2. Axially magnetized circular permanent magnet made up of strontium-ferrite are used in the system. Under normal operating condition the system is stable in the radial direction and is unstable along the axial direction. The stability along the axial direction is achieved by the current controlled electromagnet. The rotor is rotated by normal supply frequency induction motor placed in between the upper and lower magnetic bearing. The flywheel is placed at the top of the system. The total mass of the rotor is $5.5 \mathrm{~kg}$. The repulsive forces between the permanent magnets and the attractive force between the rotor and the electromagnet are acting in the same direction and combinedly levitate the rotor. The gap-sensors are used to measure the gaps between the rotor surface and the electromagnet and are scaled to give an output of $1 \mathrm{~V} / \mathrm{mm}$.

\section{Model for field analysis}

The magnetic bearing has been analyzed with the help of finite element model. The mesh model for the analysis and the axes are shown in Fig. 3. Z-axis is the vertical axis. Since the rotor is shifted with respect to the stator, full model has been considered here. The analyses corresponding to different configurations are carried out, only two patters as shown in Figs $4 \mathrm{a}$ and $4 \mathrm{~b}$ are shown here.

A section of the rotor (Fig. 4a) and the stator (Fig. 4b) are assumed to have different field intensity with respect to other part and the remaining part is assumed to have uniform field intensity. The distribution of flux-density and forces are calculated from the post-processing. The forces at two opposite ends are different leading to displacement of the rotor. By shifting the rotor the fields are analyzed and the stable position is assumed corresponding to the equal forces at two opposite sides of the rotor. 




Fig. 2. Permanent magnet configuration.

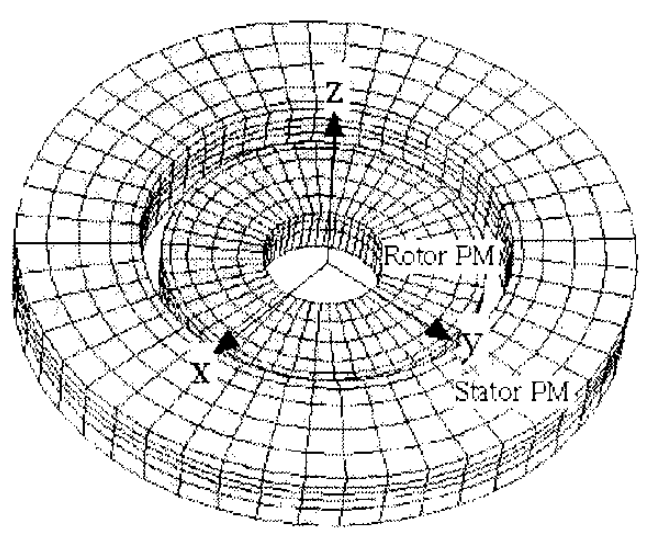

Fig. 3, Model for field analysis.

\section{Simulation results}

The field distribution has been analyzed assuming different magnetizations of the black section such as $100 \%, 80 \%, 60 \%$ and $40 \%$ of the remaining part. For different displacements of the rotor along $\mathrm{X}$ and $\mathrm{Y}$ axis, the forces are calculated from field analysis. The stability of the rotor is assumed to be maintained when the equal forces are acted on the rotor at two opposite sides. Figure 5a shows the displacement of the rotor for the pattern \#1 shown in Fig. 4a for different magnetization. Figure 5b shows corresponding to pattern \#2. It is seen that when the non-uniformity takes place only in the rotor, it rotates keeping 


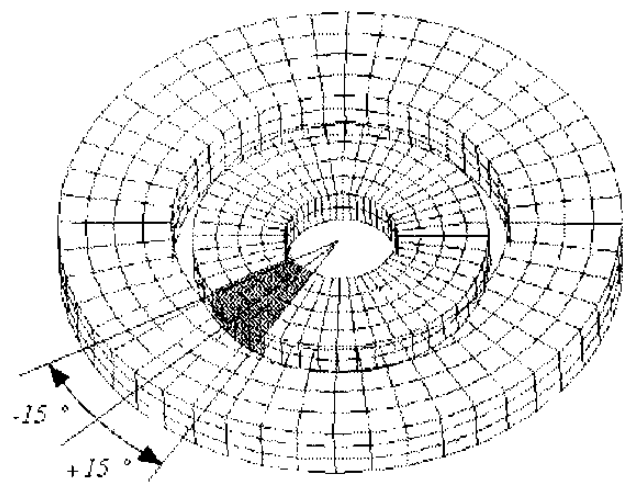

Fig. 4a. Pattern \#! Non-uniformity in the rotor.

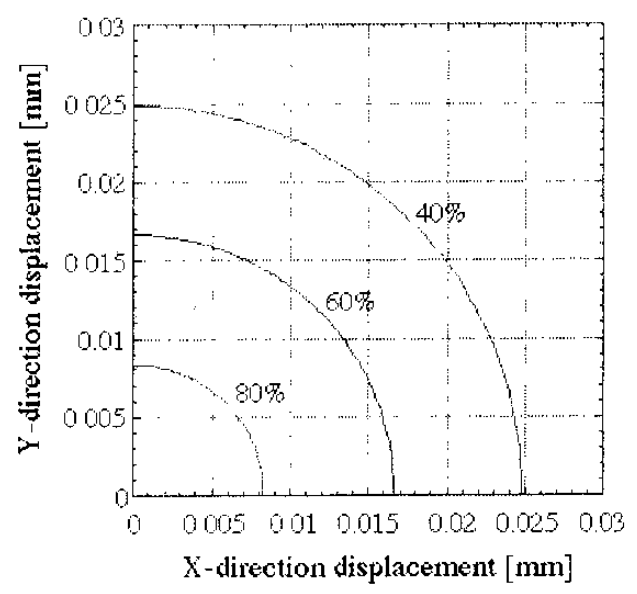

Fig. 5a. Displacement of the rotor (Pattern \#1).

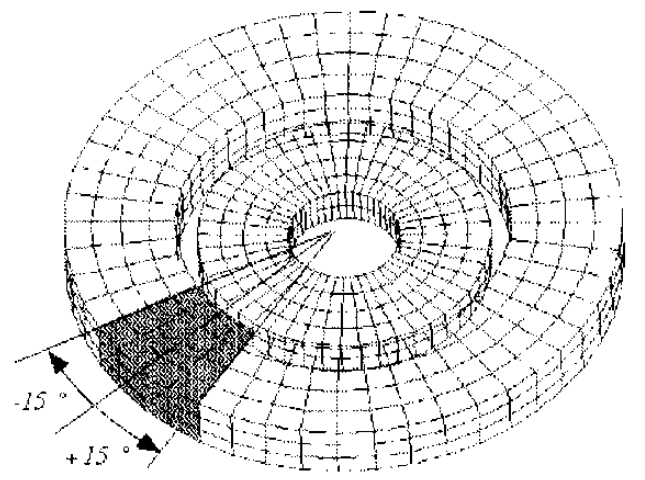

Fig. 4b. Pattern \#2 Non-uniformity in the stator.

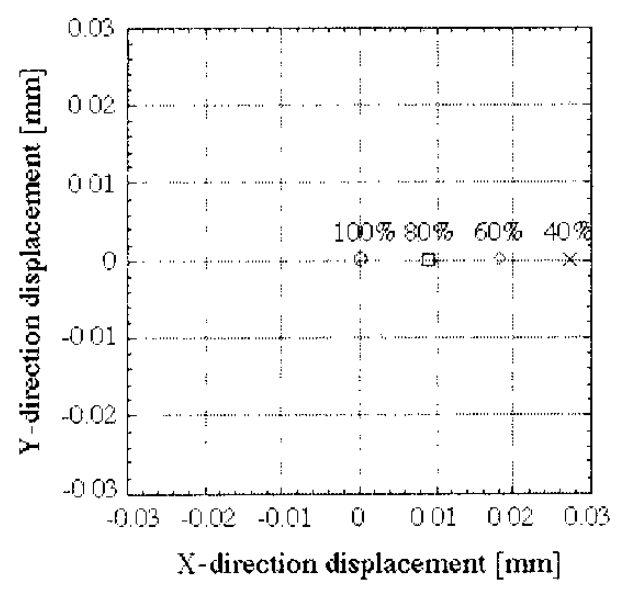

Fig. 5b. Displacement of the rotor (Pattern \#2).

the center line in the original position but with a displacement along the radial direction. In the case of Fig. 5b, the rotor is displaced from the stator non-uniformity section along the $\mathrm{X}$-axis as shown.

\section{Experimental results}

It is difficult to get permanent magnet of desirable magnetization. For the experiment the old magnets available in the laboratory are used which are demagnetized due to ageing. The characteristics of permanent magnets are measured with the help of gaussmeter. The rotor chosen is of uniform magnetization. The stator section has strong as well as weak magnetization part. With this stator the experiments are conducted. Figures $6 \mathrm{a}$ and $6 \mathrm{~b}$ show the displacement characteristics of the rotor at $300 \mathrm{rpm}$ and $1800 \mathrm{rpm}$ respectively. It is seen that the rotor has been displaced from the center point towards the weak magnetization section. The amplitude of oscillation at $300 \mathrm{rpm}$ is comparatively large. Since the natural frequency of oscillation of the rotor is low (around $500 \mathrm{rpm}$ ), this might have some effect on low speed 


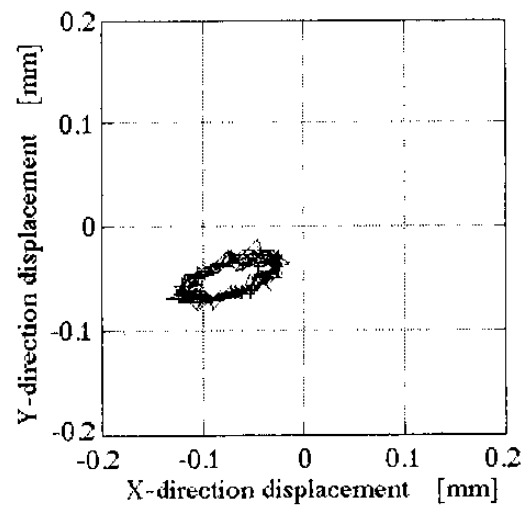

Fig. 6a. Displacement characteristics at $.300 \mathrm{rpm}$.

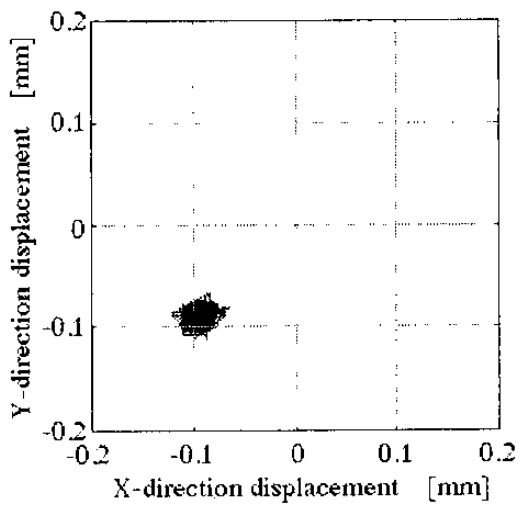

Fig. 6h. Displacement characteristics at $1800 \mathrm{rpm}$.

of operation. It is seen from Figs $6 \mathrm{a}$ and $6 \mathrm{~b}$ that due to non-uniformity of the magnetization the rotor is displaced from the center position. If the difference of magnetization becomes large, the rotor may hit the stator inner surface and the operation becomes impossible.

\section{Conclusions}

This paper has studied the effect on non-uniformity of the magnetization of the permanent magnet on the performance of repulsive type magnetic bearing. It has been shown both by field analysis and experiments that the rotor is displaced from the center position due to the non-uniformity. It is very important to specify quantitatively the relationship between this non-uniformity of magnetization and the limit of stability. Some more experimental results are required for that purpose.

\section{References}

[1] S.C. Mukhopadhyay, T. Ohji, M. Iwahara and S. Yamada, IEE Proc. - Electric Power Application 146(1) (Jan. 1999), 3.-40.

[2] S.C. Mukhopadhyay, T. Ohji, M. Iwahara, S. Yamada and F. Matsumura, Journal on Non-finear Electromagnetic sy'stems, IOS Press, 1998, pp. 741-744.

13] S. Ueno, H. Kanebako, T. Yaname and Y. Okada, Joumal of the Japan Society of Applied Electromagnetics and Mechanics 8(2) (June 2000), 239-245.

[4] R. Takahata, H. Higasa, H. Ueyama, Y. Miyagawa, H. Kameno and H. Ishikawa, The Transactions of IEE Japan 117-D(9) (Sep. 1997), 1132-1138. 